\title{
Mortality in a cohort of diabetic patients
}

\section{Causes and relative risks}

\author{
N. R. Waugh ${ }^{1}$, J.H. Dallas ${ }^{1}$, R. T. Jung ${ }^{2}$ and R. W. Newton ${ }^{2}$ \\ ${ }^{1}$ Tayside Health Board, and ${ }^{2}$ Ninewells Hospital, Dundee, UK
}

Summary. In a prospective study of mortality in a large group of Scottish diabetic patients, ischaemic heart disease was responsible for $51 \%$ of deaths, with the diabetic relative risks of death being 3.8, 2.7 and 2.2 for the age groups 45-64, 65-74, and 75 years and over, respectively. The diabetic relative risks for mortality from all causes were 5.5, 2.3, 1.7, 1.3 for age ranges $15-44,45-64,65-74$, and 75 and over, respectively. The all cancer mortality rate is not reduced in diabetic individuals.

Key words: Diabetes, mortality, relative risks.
Mortality from diabetes has been underestimated in the past, for reasons which include under-reporting of diabetes on death certificates, or its inclusion as a contributory cause, rather than as an underlying cause [1,2]. In terms of total population mortality, the impact of diabetes may be four to five times as great as indicated by routine statistics [1]. Because of the under-reporting, there are advantages in starting with a cohort of diabetic patients, and collecting mortality data prospectively. We report here the early findings of such a study.

\section{Subjects and methods}

The cohort consisted of two roughly equal groups of patients. The first comprised all the patients on our validated population-based register of insulin-treated patients, constructed as described elsewhere [3]. The second group was drawn from non-insulin treated patients attending the Ninewells Hospital Diabetic Clinic. The latter group is not representative of all non-insulin treated patients, since in Tayside about one-third of all diabetic patients do not attend hospital clinics, with hospital attenders tending to be younger than the average. All patients were alive at the end of 1984.

The records of the patients were flagged at the National Health Service Central Register and copies of death notifications obtained. Death rates were calculated for the 3.25 year period to the end of March 1988. Rates for the Tayside population were obtained from Scottish Health Statistics 1986/87, Table 2.2, which gives mortality for selected causes by age and health board [4]. Comparison of rates was done using $t$ tests on proportions. The Tayside rates are for the general population of Tayside (circa 380,000) and are included for comparison with other areas and countries. They do, of course, include diabetic patients, including not only those in this study, but those who were not, some of whom will be undiagnosed. Ischaemic heart disease mortality in Tayside is near the average for Scotland, which has a higher rate than England and Wales.

\section{Statistical analysis}

Relative risks (odds ratios) and confidence limits are calculated as described by Morris and Gardner [5], with the diabetic deaths and denominators subtracted from those for the Tayside population, obtained from Tables 2.2 and 1.2 of the Scottish Health Statistics [4]. All death notifications were checked by one observer, and case notes consulted if the true cause was not clear from the certification. Heart disease comprises International Classification of Disease [6] codes 410-414, cancer codes $140-239$, and stroke codes $430-438$. 95\% confidence limits are given in brackets after relative risks. If numbers of deaths are too low for analysis, the rate or risk is given in brackets. The number of diabetic patients in each age group is shown at the top of the table. There were no deaths in the $0-14$ age group, and that column has been omitted.

\section{Results}

Numbers, rates per annum, relative risks and 95\% confidence intervals are shown in Table $1.51 \%$ of all diabetic deaths were from ischaemic heart disease, compared to $34 \%$ of deaths in non-diabetic subjects. In the age range $45-74,55 \%$ of deaths in the diabetic group were due to heart disease, compared to $38 \%$ of nondiabetic deaths. Only $13 \%$ of the diabetic deaths were due to cancers, compared to $22 \%$ of non-diabetic deaths, but the actual death rates from cancer were similar. The striking features are the increased allcauses and heart disease death rates in diabetes. The relative risk declines with age.

Diabetes was mentioned, either as an underlying or contributory cause, on only $70 \%$ of death certificates. 
Table 1. Rates and relative risk of death

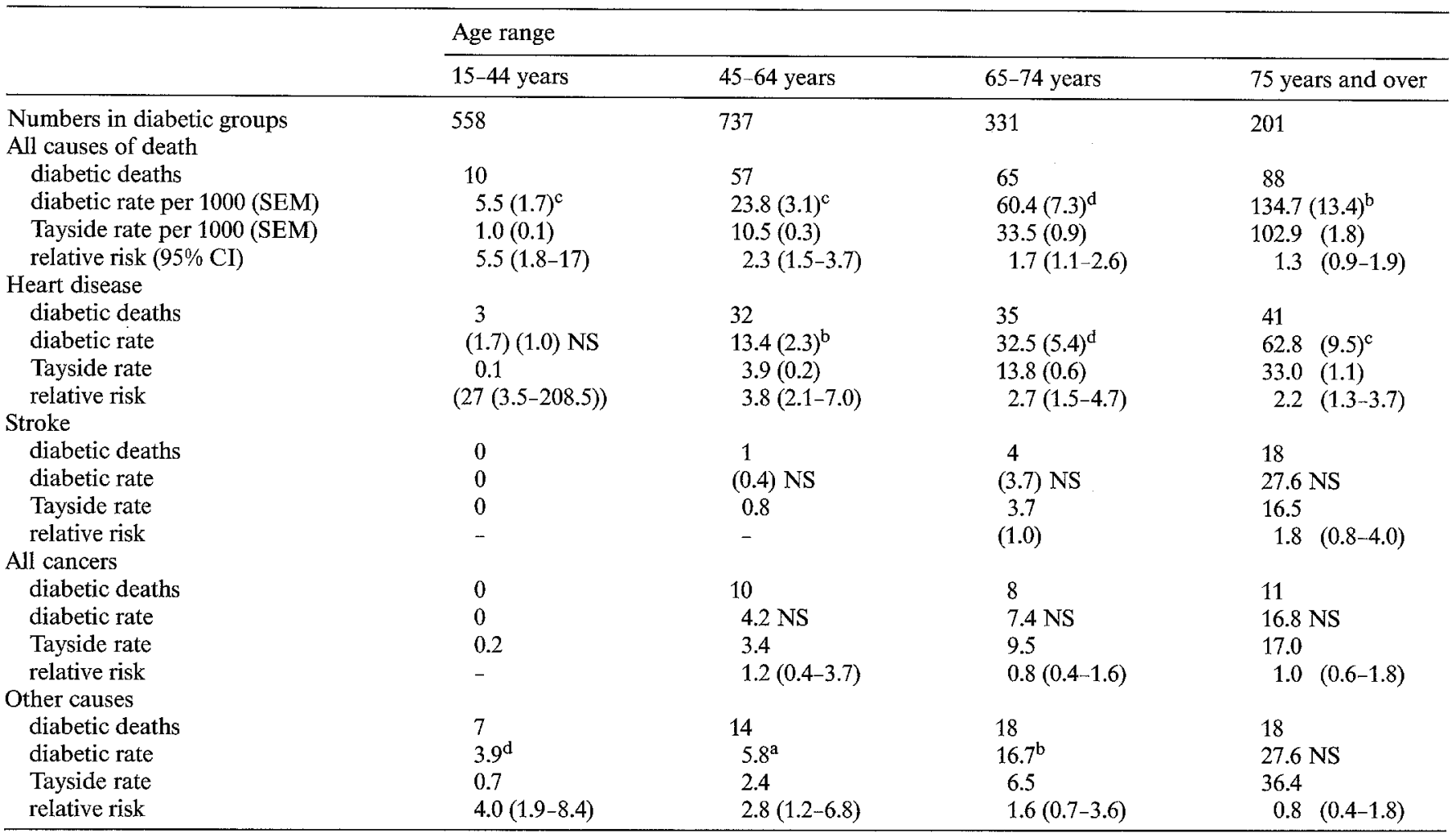

$p$ values refer to comparison of diabetic rate with Tayside rate. NS $=p>0.05 ;{ }^{\mathrm{a}} 0.05>p>0.02 ;{ }^{\mathrm{b}} 0.02>p>0.01 ;{ }^{\mathrm{c}} 0.01>p>0.001 ;{ }^{\mathrm{d}} p$ less than 0.001. Confidence interval (CI)

\section{Discussion}

A previous British study [1], based only on death certificates mentioning diabetes, suggested that the risk of cancer was less in diabetes. This paper shows that although the proportion of deaths from cancer is lower in the diabetic group than the general population, the actual rates are similar. The greatly increased risk of heart disease in diabetes is not offset by a lower cancer risk.

The relative risk of death from heart disease in Tayside diabetic patients is higher than in the United Kingdom as a whole [1] and East Germany [7]. This supports the findings from Finland that the diabetic relative risk of heart disease is even higher when the non-diabetic risk is higher [8].

Diabetic services are under review in a number of areas of the United Kingdom $[9,10]$. The findings of this study show that prevention of ischaemic heart disease should be a major concern of diabetic clinics.

Acknowledgements. We are grateful for the assistance of the National Health Service Central Registers in Edinburgh and Southport, of the Primary Care Division of Tayside Health Board, to Mrs M. Foster and Mrs A. Wares for data collection and typing support, and to the Chief Scientist Organisation of the Scottish Home and Health Department for a research grant to fund the study.

\section{References}

1. Fuller JH, Elford J, Goldblatt P, Adelstein AM (1983) Diabetes mortality: new light on an underestimated public health problem. Diabetologia 24: 336-341
2. Tunbridge WMG, for Medical Services Study Group (1981) Factors contributing to deaths of diabetics under fifty years of age. Lancet II: 569-572

3. Waugh NR, Jung RT, Newton RW (1987) Proteinuria prevalence in insulin-treated patients: prediction of need for end-stage renal failure treatment. Diabetic Med 4: 151-155

4. Information Services Division of Scottish Home and Health Dept (1987) Scottish Health Statistics 1986/87. Edinburgh

5. Morris JA, Gardner MJ (1988) Calculating confidence intervals for relative risks (odds ratios) and standardised ratios and rates. $\mathrm{Br}$ Med J 296: 1313-1316

6. World Health Organisation (1977) Manual of the international classification of diseases, injuries and causes of death. 9th rev. Geneva WHO

7. Panzram G, Zabel-Langhennig R (1981) Prognosis of diabetes mellitus in a geographically-defined population. Diabetologia 20 : 587-591

8. Laakso M, Ronnemaa T, Pyorala K, Kallio V, Puukka P, Penttila I (1988) Atherosclerotic vascular disease and its risk factors in non-insulin dependent and non-diabetic subjects in Finland. Diabetes Care II: 449-463

9. Scottish Home and Health Dept (1987) Report of the Working Group on the Management of Diabetes. Edinburgh. HMSO

10. Williams DRR (1988) Spreading the message. Diabetic Med 5:93

Received: 31 October 1988

and in revised form: 20 December 1988

Dr. N.R. Waugh

Tayside Health Board

Vernonholme

Riverside Drive

Dundee DD1 9NL

Scotland

UK 